for both animal and plant tissues. Section five, on single-cell isolation and cloning, contains articles dealing with most of the standard techniques. Section six presents a series of articles on perfusion and culture techniques. Section seven, on cell propagation on miscellaneous culture supports, deals with the use of materials such as polyester sheeting, cellulose sponge and titanium discs. Section eight, on the evaluation of culture dynamics, is concerned mainly with methods for counting cells; it also contains two articles on cell-cycle analysis. Section nine is entitled " Recent techniques facilitating microscopic observations of cells" and is a miscellaneous collection of articles dealing mainly with embedding methods and microscopic techniques. Section ten has several contributions on cell hybridisation. Section eleven has eight articles on virus propagation and assay. Section twelve presents eight articles on the production of hormones and intercellular substances, such as collagen. Section thirteen deals with the diagnosis and understanding of disease; it contains details of the culture of cells from a variety of genetic disorders such as Hurler's syndrome and Maple Syrup Urine disease. Finally, section fourteen entitled "Quality control measures" has thirty miscellaneous contributions covering a wide range of subjects from the preparation and sterilisation of glassware, water and sera to the karyology of cells in culture.

As this list indicates, the coverage is extensive although not completely comprehensive, for there are a few omissions such as plasma-clot cultures, which the editors have left out deliberately. The quality of the articles varies greatly but, on the whole, is high. Many technical methods are given in considerable detail. One or two of the articles are quite authoritative; I would particularly single out the chapter on the production and characterisation of proliferating somatic cell hybrids by Giles and Ruddle, which is one of the most comprehensive reviews of the present state of this field available and the article "Malignant transformation of cells in culture using oncogenic chemicals by Heidelberger, Reznikoff and Krahn, which is again authoritatively written. By and large, however, it is not a collection of reviews but rather a recipe book with rather brief accounts of methods written by people who have used them. It is amost inevitable that there should be some repetitiveness in such a large collection; in a few instances, there are several accounts of similar procedures but these are quite few.

There is a profusion of references which appear as footnotes throughout the text. These are completely indexed in an Author Index and the entire text has been carefully indexed in a Subject Index. The volume is produced in typical Academic Press high-quality format and the surprisingly reasonable price is due to the fact that it was subsidised by a grant from the Samuel Robertson Noble Foundation.

The book is not for beginners in tissue culture; nor is it the kind of volume that is likely to be used as a classroom text. But it is likely to prove a most useful book of reference and an essential addition to the library of all laboratories in which tissue culture methods are used or are likely to be used.

JoHN PaUL

\title{
Current Antibiotic Therapy
}

Ed. by A. M. Geddes and J. D. Williams. 1973. Edinburgh and London: Churchill Livingstone. Pp. Xv and $251 ; 23$ text figures. £3.00.

This book is based on a symposium entitled "Antibiotics after Thirty Years", held at Birmingham in 1972. The symposium brought together microbiologists and clinicians who provided a wide range of expertise and plenty of scope for cross fertilisation of ideas. It was felt to be a particularly successful occasion by all who attended and it is gratifying to see the session recorded in a permanent form.

The design of the symposium certainly contributed to its success, as well as the generally high quality of the individual contributions. Dialogues and round-table discussions formed a supporting framework for the programme of specialised papers and set the general tone of laboratory-clinical cooperation which made the occasion so pleasant. The discussions appear to have been published unabridged. The first of these is "Antibiotics in perspective ", a dialogue between Professors H. P. Lambert and F. W. O'Grady, which reviews the current state of antibiotic therapy, with salutary emphasis on the role of non-antibiotic factors in the 
reduction of mortality from infectious disease and the need to study the optimum use of antimicrobials and to continue research into the host-parasite relationship. The mid-point of the symposium is a very useful round-table discussion on "Antibiotic use in hospital ", chaired by Dr E. J. L. Lowbury, and the final round-table discussion is on "Antibiotics in prospective ", an interesting look into the future, chaired by Professor O'Grady. These sessions all have an up-to-date and obviously practical approach, not merely to individual therapy but to antibiotic strategy. They emphasise narrow-spectrum therapy and close laboratory-clinical co-operation in tailoring specific therapy for individual infections. This is seen as the best alternative to broad-spectrum therapy, which has probably promoted the spread of resistance in the past.

The individual papers in the Symposium cover wide ranging topics such as "Untoward reactions to antibiotic therapy" and "The use of antibiotics and resistance", and specific problems such as treatment of urinary-tract and respiratory-tract infections, as seen by both clinicians and microbiologists. More specialised subjects, such as neonatal infection, venereal disease and endocarditis after cardiac surgery, are also covered by experts in these fields.

The symposium will be of interest not only to microbiologists, but also to their clinical colleagues and to those who teach the more senior medical students who already have got some insight into modern antibiotic problems and want to know what we propose to do about them.

A. C. MADDOCKS

\section{Agents of Bacterial Disease}

By A. S. KLAINer and I. GeIs. 1973. Hagerstown, Maryland, USA: Harper and Row. Pp. xvi and 168. $£ 7 \cdot 20$.

This is intended to be a basic introductory book for medical students and attempts to cover a large field without becoming unwieldy. The test is crisp and concise, but oversimplification results in some ambiguity and omissions. There are many excellent diagrams and line drawings by which the authors intend that learning should be " primarily visual ". It is doubtful, however, whether the rather extravagant use of electron micrographs successfully gives a student insight into the nature of bacteria; this approach must have increased production costs considerably.

Modern concepts of bacterial structure and function are adequately conveyed, except that sex fimbriae (pili) are only briefly mentioned alongside common fimbriae; the role of conjugation deserves more emphasis. The systematic coverage of the major groups of pathogenic bacteria is mostly clear and well balanced, although one would hope that the modern medical student would want to look more deeply into some mechanisms of pathogenicity. A major weakness is in the brief and superficial description of the Gram-negative non-sporing anaerobes.

The authors give a simple and straightforward account of the host defence system-an important aspect that is often neglected in such concise books. It is unfortunate that they do not go on to discuss the role of the host reaction in producing the clinical manifestations of infection. The changing pattern of medical bacteriology is usefully emphasised by the comprehensive section on opportunist infection and the compromised host situation.

The content and emphasis of this book should be of interest to many medical students, but its presentation as a "student's handbook" with fewer electromicrographs might have been more appropriate and would have been less expensive.

\section{B. I. DUERDEN}

\section{Principles of immunology}

Ed. by Noel R. Rose, Felix Milgrom and Carel J. van Oss. 1973. London and New York: Cassell and Collier Macmillan Publishers Ltd. Pp. $x$ and 468; 77 text figs. $£ 7.50$ ( $£ 4.95$ in paperback).

With the rapid development in immunology over the last 10 years have come increasingly more meaningful approaches to medical problems that can be understood in immunological 